\title{
Acculturation Strategies of Chinese University Students in the United States
}

\author{
Xinying Xing ${ }^{1}$, Michael Popp ${ }^{2}$, Heather Price ${ }^{2}$ \\ ${ }^{1}$ School of Western Studies, Heilongjiang University, China \\ ${ }^{2}$ Department of Agricultural Economics and Agribusiness, University of Arkansas, USA \\ Email: 2001085@hlju.edu.cn
}

\begin{abstract}
Acculturation strategy choices of Chinese students in the U.S. were analyzed in relation to demographic and intercultural contact factors to assess their impact on social adaptation and selfreported anxiety and depression. Integration and marginalization were the most and least common acculturation strategies, respectively. Demographic variables had no statistically significant impact. Rank ordered multinomial logit analysis showed language proficiency and instrumental motivation to learn the language as well as association with U.S. and Chinese cultures to play a significant role. This empirical evidence can help Chinese students with social adaptation, anxiety and depression in the U.S. by providing guidance on how to match students to university programs.
\end{abstract}

Keywords: Acculturation strategy, language proficiency, cultural identity, psychosocial adjustment

\section{Introduction}

In the 2016-17 academic years, 350,755 Chinese students were pursuing higher education in the United States. Chinese students represented $32.5 \%$ of the total enrollment of international students in the United States in that year. China has also been the top sending country for the ninth consecutive year since 2009 (Institute of International Education, 2017). Adjusting to a new culture, the process of acculturation can be a challenging and stressful experience. Acculturation is defined as a group-level phenomenon when people from different cultures come into first-hand contact and subsequently bring out changes in either or both cultures (Redfield et al., 1936). Graves (1967) examined individual-level acculturation, focusing on the psychological changes in group members' world view when in contact with another culturally distinct group. Later research incorporated behavior, values, and cultural identity into psychological acculturation. Berry (2005) conceptualized acculturation as the process of cultural and psychological change building on earlier work that argued for four acculturation strategies, assimilation, separation, integration, and marginalization (Berry et al., 1989). Assimilation (A) is a preference for interacting with and expressing a desire to understand the host culture while disconnecting with the home culture. Separation (S) occurs when cultural maintenance with the home country is desired while avoiding involvement with the host culture. Integration (I) is present when both cultural maintenance and involvement with the host culture are sought. Marginalization (M) exists when neither cultural maintenance nor interaction with the host culture is sought.

Given the size of their contingent, Chinese students have gained substantial social recognition and support but may still encounter considerable acculturative stress because of the differences in academic and social norms between Chinese and U.S. culture (Yeh \& Inose, 2003). Previous studies found that for Chinese students a lack of English proficiency is the greatest barrier in the academic adjustment process as language barriers and communication problems are stressors (Yan \& Berliner, 2011; Zhou \& Zhang, 2014). In addition, with the firm belief in humbleness, modesty, saving face, and emotional restraint in social contexts, Chinese international students may encounter difficulties in fitting in with the American social format that features directness and assertiveness in expressing feelings (Wang \& Mallinckrodt, 2006). The adjustment difficulties encountered by Chinese students indicate the possible challenges faced by international students in the U.S. The acculturation strategy international students pursue and its impacts have, thus, received increasing scholarly attention.

Demographic variables like gender, age, duration of stay, and region or country of origin dominate among predictors of acculturation strategy (Berry et al., 1989; Barry, 2001; Leong \& Ward, 2000; Ward 
\& Kennedy, 1996). During acculturation, however, individuals' prior attitudinal preconceptions are also confronted with new lifestyles and, hence, language proficiency and cultural identity have been considered central intercultural variables (Berry et al., 2006; Duru \& Poyrazli, 2007; Neto, 2002; Poyrazli, 2003; Hui et al., 2015; Yang et al., 2006). Additionally, psychosocial adjustment variables like stress in academic and daily life, social support, and cross-cultural self-efficacy can be significant outcomes of acculturation strategy choice (Ward \& Kennedy, 1999; Zhou et al., 2008; Ng et al., 2017). Psychological adjustment can be measured using self-reported psychological symptoms (isolation, helplessness, sadness, feelings of loss, etc.) and perceived distress that manifests itself as stress and coping mechanisms (Ward \& Kennedy, 1999). On the other hand, sociocultural adjustment refers to the ability to fit in, to acquire culturally appropriate skills, and to negotiate interactive aspects of the host environment (Ward \& Kennedy, 1999). Research to date suggests that people who identify more with their home culture experience less anxiety and depression symptoms, whereas people who identify more with the host culture experience less difficulties in sociocultural adaptation (Bektas, et.al, 2009; Berry, 1997; Berry et al., 1989; Hendrickson et al., 2011; Neto, 2002; Poyrazli, 2003; Ward \& Rena-Deuba, 1999; Yu \& Wang, 2011; Zhang \& Goodson, 2011).

Given the aforementioned body of work, this study has three objectives. First, acculturation strategies of Chinese university students in the U.S. were examined to determine which strategy was most common. Second, demographic and intercultural contact factors were examined to assess their impact on choice of acculturation strategy. Demographic factors included age, gender, length of residence and level of academic achievement sought (undergraduate or graduate). Intercultural contact factors involved language motivation, language proficiency, and cultural identity. Finally, the effect of demographic and intercultural contact factors along with acculturation strategy on psychosocial adjustment as reflected in self-reported psychological problems and social adaptation were examined. Findings are expected to assist international program coordinators develop programs for Chinese students that reduce stress and enhance academic success.

\section{Materials and Methods}

\subsection{Subjects}

One hundred Chinese students from universities in Arkansas participated in the study. Five respondents were born in the U.S.; their data were excluded from the study. Of this sample, 48 were male and 47 were female. Subjects ranged in age from 18 to 35 years old. The length of residence in the U.S. varied from 3 months to 12 years and the majority of students were studying at the undergraduate level at the time of the survey (Table 1). These demographics are deemed representative of Chinese students in the U.S. but degree of representativeness could not be tested statistically. Subjects were contacted through the Chinese Students and Scholars Association in each university.

Table 1. Description of age, length of stay, gender and student career stage of Chinese students, Arkansas, 2017.

\begin{tabular}{|c|c|c|c|c|}
\hline Variable & Min & Max & Avg. & Std. Dev. \\
\hline AGE (of survey respondent in years) & 18 & 35 & 23.24 & 3.27 \\
\hline LENGTH (of time in country at time of survey in years) & 0.2 & 12 & 3.33 & 2.38 \\
\hline & \multicolumn{2}{|c|}{ Female } & \multicolumn{2}{|c|}{ Male } \\
\hline \multirow[t]{2}{*}{ GENDER (\# of respondents) } & \multicolumn{2}{|c|}{47} & \multicolumn{2}{|c|}{48} \\
\hline & \multicolumn{2}{|c|}{$\begin{array}{c}\text { Undergraduate } \\
\text { (Freshman - Senior) }\end{array}$} & \multicolumn{2}{|c|}{$\begin{array}{c}\text { Graduate } \\
(\mathrm{MSc} \text { or } \mathrm{PhD})\end{array}$} \\
\hline GRAD (\# of respondents by student career stage) & \multicolumn{2}{|c|}{67} & \multicolumn{2}{|c|}{28} \\
\hline
\end{tabular}

Note: Scales are described in the introduction and materials and methods section of the text. High scores indicate preference toward a particular acculturation strategy (A, S, I, M), high motivation to learn the host language, high language proficiency (LP), strong acceptance of country association (US \& CH), strong ability to interact in social settings (ADAP), and high incidence of self-reported psychosomatic symptoms associated with anxiety and depression (ANXDEP) using a 5-point Likert scale. 


\subsection{Questionnaire}

A questionnaire (Appendix A) was developed and administered in conjunction with a standard set of instructions, which informed students that participation was voluntary, that responses were confidential, and that responses would be confined to academic purposes only. Fifty-four subjects filled out the paperand-pencil questionnaire during the spring 2017 semester at the University of Arkansas in Fayetteville. The author was present to supervise data collection. Another 41 subjects filled out an electronic questionnaire for students at Arkansas State University, and University of Arkansas satellite campuses. The questionnaire assessed a wide range of variables related to acculturation and adaptation using 53 questions. The first section was used to elicit acculturation strategy preferences, and the second section analyzed motivations and proficiency in target language learning. The last section elicited social and psychological adjustment factors. The questionnaire was administered in English.

The subscales in the three sections were either taken directly from or with modification to existing scales as described below. With the exception of demographic items, all the items reported here were answered on a 5-point Likert scale ranging from (1) "strongly agree" to (5) "strongly disagree."

Acculturation Strategies. Using the 26-item scale developed for International Comparative Studies of Ethnocultural Youth (ICSEY) by Berry et al. (1989) and the East Asian Acculturation Measure (EAAM) by Barry (2001), four dimensions of acculturation, as described above, were used to assess assimilation, separation, integration, and marginalization across six domains: marriage, cultural traditions, language, social activities, friends, and music. Examples of items examining each of the subscales are: "I find it that Americans understand me much better than Chinese do" (assimilation); "I prefer going to social gatherings where most of the people are Chinese" (separation); "I feel very comfortable around both Americans and Chinese" (integration); "I sometimes feel that neither Americans nor Chinese like me" (marginalization).

Language motivation. Using Gardner \& Masgoret's (2003) Attitude/Motivation Test Battery (AMTB) respondents were asked two questions to determine their instrumental motivation to learn English. Instrumental motivation occurs when the target language is acquired for pragmatic purposes without any interest in socially integrating with the target language community (Gardner \& Masgoret, 2003). High integrative motivation scores, in comparison, reveal also a desire for social integration.

Language proficiency. The scale of language proficiency inquired about a person's abilities to understand, speak, read, and write the language (Berry et al., 2006). The target language proficiency is assessed with eight items to self-evaluate their language skills. This scale is an adaption of a school adjustment scale from the ICSEY questionnaire and English as a Second Language (ESL) program guide developed by the Department of Defense Education Activity. Three items were used to measure language competence in higher education settings. An example is "I can participate in class discussion in fluent English." The other five questions were developed to measure communicative skills in daily social settings. An example is "I can understand Americans and respond to them well orally and in writing." The score for language proficiency was derived by reverse-scoring negative items and summing across the items so that higher scores express a relatively higher communication competence in social and academic life.

Because only two-fifth of the subjects reported their IELTS or TOEFL score as an estimate of their English proficiency, the eight-item scale discussed above was used to analyze language proficiency effects on acculturation strategy.

Cultural identity. Cultural identity was assessed using four items drawn from the Multigroup Ethnic Identity Measure (Phinney \& Devich-Navarro, 1997) to measure attitudes toward one's ethnic or national group. An example is "I love Chinese culture, history, and traditions." Another example is "I prefer Western music to Chinese music." A cultural identity score was derived by reverse-scoring negative items and summing across the items so that high scores indicated a strong Chinese or U.S. cultural identity whereas low scores demonstrated a lesser identification with either China or U.S.

Psychosocial adjustment factors. Social adaptation and psychological adaptation scales were based on Furnham \& Bochner's (1982) Social Situations Questionnaire and Ward \& Kennedy's (1999) work on the Sociocultural Adaptation Scale (SCAS). Ten items are commonly used to measure social adaptation capturing a variety of characteristics of sojourning respondents (Ward \& Kennedy, 1999). Three items were used in this study to assess the amount of difficulty subjects experience in social settings (e.g. making friends, getting used to the pace of life). Four of them, such as making yourself understood and 
talking about yourself with others, were evaluated in the acculturation strategy of the first section of the questionnaire to avoid repetition in a later section. The social adaptation score was calculated by reverse scoring negative items and summing across the items so that high scores represented less social difficulty in negotiating the host culture.

The psychological problem score was developed based on the Self Rating Depression Scale (Zung, 1965), which is widely documented for cross-cultural reliability and validity. In addition, the Profile of Mood States (McNair et al., 1971) was used given its inclusion of classic "culture shock" symptoms of tension, depression, anger, fatigue, and confusion. Sample items included "I feel tired," "I feel tense and anxious," and "I feel lonely even if I am with people." High scores correspond to psychosomatic symptoms of anxiety and depression.

Data analysis. Data collected from the questionnaire were assessed for internal reliability using item correlation coefficients (Spector, 1992) and Cronbach's alpha (Nunnally, 1978). Further, correlation coefficients $(r)$ and their statistical significance $(p)$ were estimated to gain insight about relationships among variables measured.

To estimate the effects of respondent attributes on how they rank an acculturation strategy in relation to other strategies they could pursue, a rank-ordered logit model (exploded logit model) was estimated. A respondent's utility derived from making an acculturation strategy choice is conjectured to be a function the following explanatory variables:

$$
\mathrm{U}=\mathrm{f}(\mathrm{AGE}, \mathrm{FEMALE}, \mathrm{LENGTH}, \mathrm{GRAD}, \mathrm{LP}, \mathrm{US}, \mathrm{CH}, \mathrm{MOT}, \mathrm{A}, \mathrm{S}, \mathrm{I}, \mathrm{M})
$$

where the respondents' age in years (AGE), gender (binary variable where FEMALE $=1$ for female respondents and 0 otherwise), time in country (LENGTH in years in the U.S.), pursuit of level of education (binary variable where GRAD $=1$ if respondent was pursuing a MSc or PhD degree and 0 otherwise, language proficiency (LP) using the scale described above, U.S. and Chinese cultural association using the scale described above, and instrumental motivation for language learning (MOT) as described above (Tables 1 and 2). Acculturation strategy choices A, S, I, and M are reflected in respondent's average scale scores for each strategy with the highest-scored strategy indicating the respondent's preference. Note that integrative language motivation was not used given high correlation $(r=0.53, p<0.001)$ with instrumental language motivation scored higher than integrative language motivation as shown in Table 2.

Table 2. Descriptive statistics of scales employed using the questionnaire (Appendix A) to measure acculturation strategy adoption, motivation to learn English, language proficiency, cultural identity, social adaptation and self-reported anxiety and depression of Chinese students in Arkansas, 2017.

\begin{tabular}{lccl}
\hline Scale (Acronym) & Mean (SD) & Survey Questions Used & Source \\
\hline Assimilation (A) & $2.64(0.61)$ & $1,5,9,13,16,20,23$ & \\
Separation (S) & $3.21(0.65)$ & $2,6,10,14,17,21$ & Berry (1980) \\
Integration (I) & $3.46(0.61)$ & $3,7,11,18,25$ & Barry (2001) \\
Marginalization (M) & $2.50(0.62)$ & $4,8,12,15,19,22,24,26$ & \\
\hline Instrumental language motivation (MOT) & $4.36(0.60)$ & 30,31 & Gardner \& Masgoret \\
Integrative language motivation & $3.97(0.69)$ & $27-29$ & $(2003)$ \\
\hline Language proficiency (LP) & $3.30(0.56)$ & $32-39$ & Berry et al. (2006) \\
\hline U.S. identity (US) & $3.06(0.74)$ & 40,41 & Phinney \& Devich- \\
Chinese identity (CH) & $4.24(0.61)$ & 42,43 & Navarro (1997) \\
\hline Social adaptation (ADAP) & $3.65(0.65)$ & $44,49,50$ & \\
\hline \multirow{2}{*}{ Psychosomatic symptoms (ANXDEP) } & $3.35(0.72)$ & $45-48,51-53$ & Zung (1965), Neto (2002), \\
\hline
\end{tabular}

Note: Scales are described in the introduction and materials and methods section of the text. High scores indicate preference toward a particular acculturation strategy (A, S, I, M), high motivation to learn the host language, high language proficiency (LP), strong acceptance of country association (US \& CH), strong ability to interact in social settings (ADAP), and high incidence of self-reported psychosomatic symptoms associated with anxiety and depression (ANXDEP) using a 5-point Likert scale. 
Since a rank-ordered logit model makes use of the subject's second, third, and fourth highest scores for the acculturation strategies by optimizing a likelihood function that is the product of probabilities for sequences of rankings, not just the highest ranked score, it was chosen since it offered greater explanatory power than multivariate regression, neural network, and linear discriminant analyses also performed and available from the authors upon request. The model was estimated using maximum likelihood methods in the "mlogit" package of R (Croissant, 2013). For details of the rank-ordered logit model see Appendix B.

With determinants of acculturation strategy choice analyzed, a second set of equations, employing multivariate linear regression using statistical software, EViews v9 (Lilien et al., 2015), estimated the effects of demographic, intercultural contact factors, and acculturation strategy on social adaptation and psychosomatic symptoms of self-reported anxiety and depression as follows:

$$
\begin{gathered}
\mathrm{ADAP}=\alpha_{0}+\alpha_{1} \mathrm{AGE}+\alpha_{2} \mathrm{FEMALE}+\alpha_{3} \mathrm{LENGTH}+\alpha_{4} \mathrm{GRAD}+\alpha_{5} \mathrm{LP}+\alpha_{6} \mathrm{US}+\alpha_{7} \mathrm{CH}+\alpha_{8} \mathrm{MOT} \\
+\alpha_{9} \mathrm{~A}+\alpha_{10} \mathrm{~S}+\alpha_{11} \mathrm{I}+\alpha_{12} \mathrm{M}+\varepsilon \\
\begin{array}{c}
\mathrm{ANXDEP}=\gamma_{0}+ \\
+\gamma_{1} \mathrm{AGE}+\gamma_{2} \mathrm{FEMALE}+\gamma_{3} \mathrm{LENGTH}+\gamma_{4} \mathrm{GRAD}+\gamma_{5} \mathrm{LP}+\gamma_{6} \mathrm{US}+\gamma_{7} \mathrm{CH}+\gamma_{8} \mathrm{MOT} \\
+\gamma_{9} \mathrm{~A}+\gamma_{10} \mathrm{~S}+\gamma_{11} \mathrm{I}+\gamma_{12} \mathrm{M}+\mu
\end{array}
\end{gathered}
$$

where ADAP and ANXDEP are the social adaption and self-reported psychosomatic symptom scale scores, respectively, other variables are as described above, and $\varepsilon$ and $\mu$ are error terms.

\section{Results}

Internal reliability testing for the acculturation strategy scores revealed coefficient alpha (Nunnally, 1978 ) values of $0.78,0.72,0.62$, and 0.82 for assimilation, separation, integration, and marginalization scales, respectively. Internal consistency was measured using item-total scale score correlations with a threshold value of 0.30 (Spector, 1992). Assimilation item-total correlations ranged from 0.54 to 0.76. Separation item-total correlations ranged from 0.42 to 0.82 . Integration item-total correlations ranged from 0.47 to 0.71. Marginalization item-total correlations ranged from 0.56 to 0.84 . These tests suggested adequate internal reliability and consistency to pursue further statistical testing.

Table 3 summarizes the correlation among acculturation strategies. Negative correlations between assimilation and separation $(r=-0.33, p<0.01)$, integration and separation $(r=-0.29, p<0.01)$ as well as positive correlation between integration and assimilation $(r=0.34, p<0.001)$ corroborate findings of Barry (2001) on East Asian acculturation strategies and Yu \& Wang's (2011) investigation on Chinese students' acculturation strategies in Germany. The negative correlation between integration and marginalization suggested by the two studies, however, was not revealed in our findings. An interesting finding is the positive relationship between assimilation and marginalization $(r=0.18, p<$ 0.1 ) as they are polar opposites. Nonetheless, the magnitude of the correlation is small. Remaining partial correlations between covariates as outlined in Table 3 suggest that a number of factors can play significant roles in terms of acculturation strategy choices, social adaptation and self-reported psychosomatic symptoms but are left for discussion of the rank-ordered logit and multivariate regression analyses.

Using the average of responses to questions pertaining to the different acculturation strategies, a respondent's preferred strategy was the one with the highest average score. Table 4, shows that integration and separation strategies were the most and second most preferred strategies whereas assimilation and marginalization strategies were least preferred. Table 2 summarizes the psychometric instruments used in the survey. The statistics are similar to those previously reported by Berry (1997), Barry (2001), and Neto (2002)

Marginal effects, detailing the percentage change in the likelihood of picking a particular acculturation strategy as a result of unitary changes in explanatory variables are shown in Table 5. The model provided adequate explanatory power as reflected in McFadden's Pseudo $\mathrm{R}^{2}$ of $43.1 \%$. Further, several statistically significant coefficient estimates showed what factors had an impact on acculturation strategy choice. Among the leading explanatory variables in terms of the number of statistically significant results across all acculturation strategy choices were language proficiency, Chinese and U.S. cultural identity variables, length of stay, and instrumental motivation to learn the host country language. In contrast, demographic variables including age of respondent, gender, and academic level (GRAD) did not play statistically significant roles. 


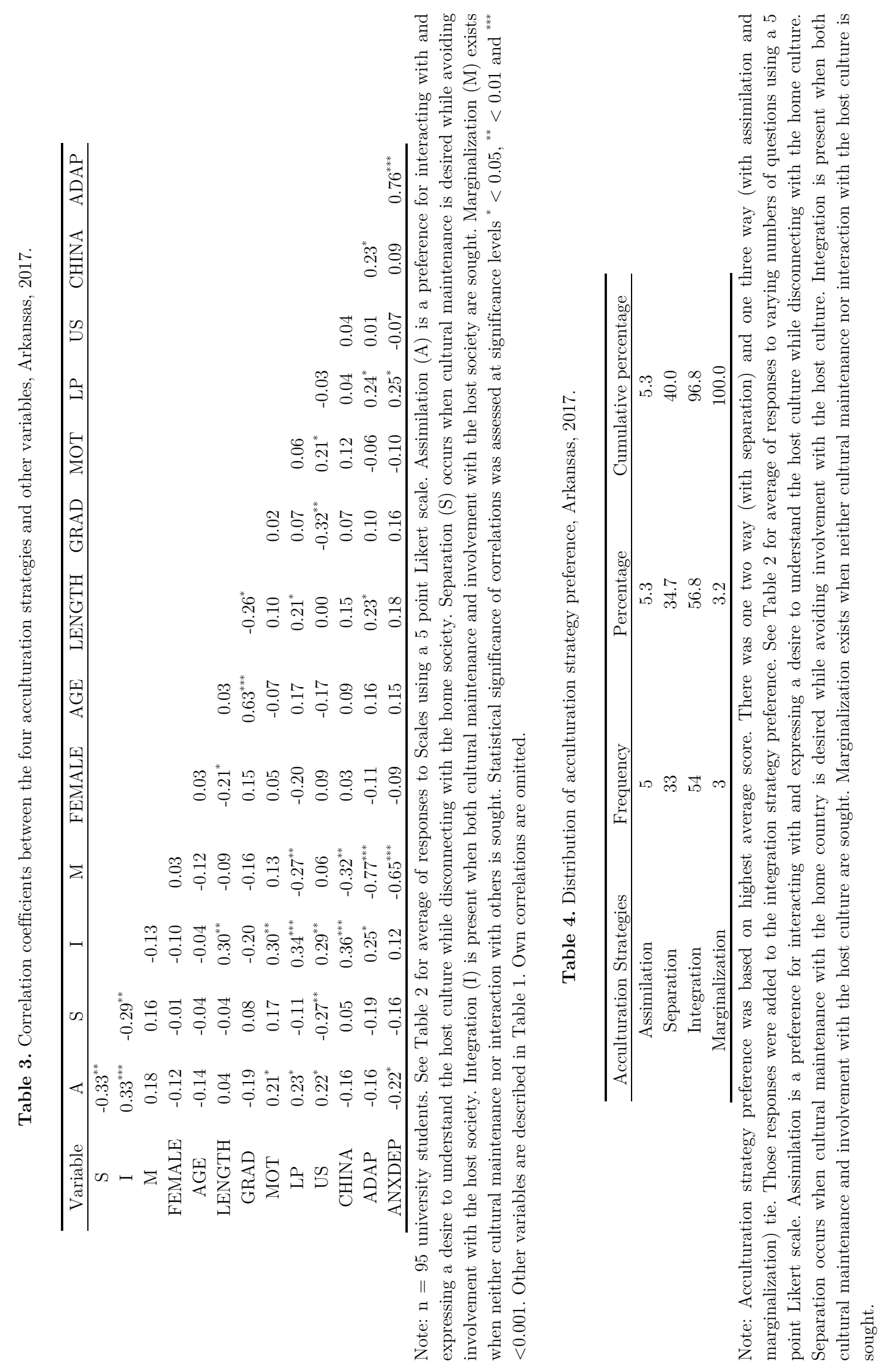


Table 5. Rank-ordered logit results indicating the estimated probability of a male, undergraduate student at mean covariate values choosing a particular strategy in the first row. Subsequent rows indicate the marginal effect of a unitary change in explanatory variables on the probability of choosing a particular strategy as their top choice.

\begin{tabular}{|c|c|c|c|c|c|}
\hline & \multicolumn{4}{|c|}{ Acculturation Strategies } & \\
\hline & Assimilation & Separation & Integration & Marginalization & \\
\hline \multirow[t]{2}{*}{ Est. Probability (\%) } & 8.16 & 2.65 & 58.43 & 6.88 & \\
\hline & \multicolumn{4}{|c|}{ Marginal Effects of Variables on Acculturation Strategy } & Std. Dev. \\
\hline AGE & -0.64 & -0.20 & 1.12 & -0.29 & 3.27 \\
\hline FEMALE & 0.17 & 8.29 & -6.11 & -2.36 & \\
\hline LENGTH & -0.10 & $-3.24^{*}$ & $3.57^{*}$ & -0.24 & 2.38 \\
\hline GRAD & -1.02 & -3.88 & 3.68 & 1.22 & \\
\hline LP & 0.22 & $-12.27^{*}$ & $19.70^{* *}$ & $-7.64^{* * *}$ & 0.56 \\
\hline US & 2.55 & $-16.63^{* * *}$ & $12.30^{*}$ & 1.79 & 0.74 \\
\hline $\mathrm{CH}$ & $-8.34^{* *}$ & -3.25 & $21.28^{* * *}$ & $-9.69^{* * *}$ & 0.61 \\
\hline MOT & 0.49 & 7.12 & -11.32 & $3.70^{*}$ & 0.60 \\
\hline
\end{tabular}

Notes: Responses for 95 individuals were used using Eq. 1. Pseudo $\mathrm{R}^{2}$ was $43.1 \%$. See Appendix B for details on marginal effects $\left(^{*},{ }^{* *}\right.$ and ${ }^{* * *}$ indicate statistically significant deviation from zero at $\mathrm{P}=0.10,0.05$ and 0.01 , respectively). Assimilation is a preference for interacting with and expressing a desire to understand the host culture while disconnecting with the home culture. Separation occurs when cultural maintenance with the home country is desired while avoiding involvement with the host culture. Integration is present when both cultural maintenance and involvement with the host culture are sought. Marginalization exists when neither cultural maintenance nor interaction with the host culture is sought. Table 1 provides summary statistics for demographic and length of stay variables. Standard deviations of other explanatory variables (Table 2) are provided in the last column to judge magnitude of marginal effects. Note that FEMALE $(1=$ female, $0=$ male $)$ and $\operatorname{GRAD}(1=$ seeking graduate degree, 0 = seeking undergraduate degree) were binary variables.

A numerically large and significantly positive relationship between LP and integration suggested that this acculturation choice is favored mostly at the cost of choosing separation and marginalization if a respondent had greater than average LP. This positive relationship strengthens results of prior studies (Berry et al., 2006; Duru \& Poyrazli, 2007; Yeh \& Inose, 2003; Yan \& Berliner, 2011; Zhou \& Zhang, 2014). Positive and significant correlation between integration and U.S. and Chinese cultural identification make sense as the integration strategy involves social integration with both the host and home cultures. At the same time, the statistically significant and sizable negative relationships between separation and U.S. cultural identification and assimilation and Chinese cultural identification make sense. The negative relationship between marginalization and Chinese cultural identification suggests that loss of cultural maintenance with the home country is perceived as low cost and perhaps as a result integration with the host culture is not deemed desirable either. The relationships between cultural identity and acculturation choice are similar to conclusions found by Berry et al. (2006) and Neto (2002).

The results on LENGTH of stay in the host country suggest that a separation strategy is preferred when students first arrive but changes to integration once they have been in country for a while. This result is in line with the study of Ying (2005) and Wei et al. (2007). They found that the length of time in the United States often has buffering effects on acculturative adjustments. Some stressors such as homesickness, cultural differences, and social isolation declined with long duration of stay. The lack of statistically significant effects of MOT on acculturation strategy choices with the exception of the positive relationship between MOT and marginalization revealed that this variable has little predictive power. Perhaps motivation to learn the language simply for pragmatic reasons reflects the lack of desire to integrate with the host culture.

With factors driving acculturation strategy choice described above, Table 6 showed statistically significant impacts of acculturation strategy on social adaptation and self-reported symptoms of anxiety and depression. Explanatory power of Eqs. 2 and 3, as reflected in R2 is adequate. Statistically significant coefficient estimates involve mainly acculturation strategy choice but also Chinese cultural identification. High social adaptation scores are positively related with the integration score as expected and negatively related with the marginalization score. At the same time, pursuit of assimilation and 
marginalization acculturation strategies are negatively related with self-reported anxiety and depression. The latter results suggest that severing ties to the home culture may reduce psychosomatic symptoms and even more so if marginalizing also the host country's culture. This conclusion conforms to the findings of Berry et al. (2006) and Hui et al. (2015) with respect to positive effects of integration on social adaptation but differs in the effects of marginalization.

Table 6. Multivariate regression of social adaptation and psychosomatic symptoms using demographic, intercultural contact and acculturation strategy choices, Arkansas, 2017.

\begin{tabular}{|c|c|c|c|c|}
\hline Variables & \multicolumn{2}{|c|}{ Social Adaptation (ADAP) } & \multicolumn{2}{|c|}{ Psychosomatic Symptoms (ANXDEP) } \\
\hline Constant & $\alpha_{0}$ & $\begin{array}{l}5.565^{* * *} \\
(0.712)\end{array}$ & 20 & $\begin{array}{l}6.295^{* * *} \\
(0.956)\end{array}$ \\
\hline AGE & $\alpha_{1}$ & $\begin{array}{c}0.016 \\
(0.018)\end{array}$ & $\gamma_{1}$ & $\begin{array}{c}-0.002 \\
(0.024)\end{array}$ \\
\hline FEMALE & $\alpha_{2}$ & $\begin{array}{l}-0.093 \\
(0.088)\end{array}$ & $\gamma_{2}$ & $\begin{array}{l}-0.081 \\
(0.118)\end{array}$ \\
\hline LENGTH & $\alpha_{3}$ & $\begin{array}{c}0.031 \\
(0.020)\end{array}$ & $\gamma_{3}$ & $\begin{array}{c}0.037 \\
(0.027)\end{array}$ \\
\hline GRAD & $\alpha_{4}$ & $\begin{array}{c}0.006 \\
(0.140)\end{array}$ & $\gamma_{4}$ & $\begin{array}{c}0.167 \\
(0.188)\end{array}$ \\
\hline LP & $\alpha_{5}$ & $\begin{array}{l}-0.070 \\
(0.089)\end{array}$ & $\gamma_{5}$ & $\begin{array}{c}0.065 \\
(0.119)\end{array}$ \\
\hline US & $\alpha_{6}$ & $\begin{array}{c}0.031 \\
(0.067)\end{array}$ & $\gamma_{6}$ & $\begin{array}{l}-0.001 \\
(0.089)\end{array}$ \\
\hline $\mathrm{CH}$ & $\alpha_{7}$ & $\begin{array}{l}-0.127 \\
(0.082)\end{array}$ & $\gamma_{\gamma}$ & $\begin{array}{c}-0.231^{* *} \\
(0.110)\end{array}$ \\
\hline MOT & $\alpha_{8}$ & $\begin{array}{c}0.018 \\
(0.083)\end{array}$ & $\gamma_{8}$ & $\begin{array}{c}0.011 \\
(0.111)\end{array}$ \\
\hline A & $\alpha_{9}$ & $\begin{array}{c}-0.134 \\
(0.085)\end{array}$ & $\gamma_{9}$ & $\begin{array}{c}-0.266^{* *} \\
(0.114)\end{array}$ \\
\hline S & $\alpha_{10}$ & $\begin{array}{c}-0.042 \\
(0.078)\end{array}$ & $\gamma_{10}$ & $\begin{array}{c}-0.108 \\
(0.104)\end{array}$ \\
\hline $\mathrm{I}$ & $\alpha_{11}$ & $\begin{array}{l}0.211^{* *} \\
(0.096)\end{array}$ & $\gamma_{11}$ & $\begin{array}{c}0.134 \\
(0.129)\end{array}$ \\
\hline M & $\alpha_{12}$ & $\begin{array}{c}-0.791^{* * *} \\
(0.078)\end{array}$ & $\gamma_{12}$ & $\begin{array}{c}-0.685^{* * *} \\
(0.105)\end{array}$ \\
\hline $\mathrm{R}^{2}$ & & $66.7 \%$ & & $50.0 \%$ \\
\hline F-stat & & 13.682 & & 6.835 \\
\hline $\mathrm{P}(\mathrm{F}$-stat $)$ & & 0.000 & & 0.000 \\
\hline
\end{tabular}

Notes: Coefficient values and their standard errors in parentheses are reported for each of Eqs. 2 and 3 using observations from 95 respondents. Table 2 describes demographic and length of stay summary statistics. Table 4 provides summary statistics on remaining variables. Assimilation (A) is a preference for interacting with and expressing a desire to understand the host culture while disconnecting with the home culture. Separation (S) occurs when the cultural identity remains with the home country only. Integration (I) and Marginalization (M) occur when both/neither cultural maintenance and/nor involvement with the host culture are sought. *, ** and *** represent statistical significance at the $0.10,0.05$ and 0.01 levels, respectively.

Somewhat countering these effects are that greater cultural identification with China leads to lesser psychosomatic symptoms. Perhaps the Chinese culture of saving face and showing emotional restraint in social contexts affected self-reporting of anxiety and depression. Comparable result could be found in previous acculturation studies (Ward \& Rena-Deuba, 1999; Poyrazli, 2003; Bektas et al, 2009) that sojourners' identification with the home culture may provide a moderating effect on anxiety and depression. 


\section{Discussion}

To address the first objective, determining how Chinese university students acculturate, we tested the multidimensional model of acculturation proposed in the literature (Berry, 1997; Barry, 2001). The largest number of students $(56.8 \%)$ revealed a preference for the integration strategy suggesting that most students consider this strategy as effective with regard to adjustment to the host country. The result was consistent with the previous studies of Zheng et al. (2004), Zhang \& Goodson (2011), and Hui et al. (2015). In our study, students with the integration preference showed a positive relationship between their strategy score and Chinese and U.S. cultural association, language proficiency, and length of stay in the US. These results partially replicated the findings by Berry (1997) and Berry et al. (2006) in that language proficiency and cultural identity (both national and ethnic) contributed significantly toward choosing an integration strategy. The direct relationship between language proficiency and integration also supported studies of Yang et al. (2006).

The second largest group (34.7\%) choosing separation as a strategy, placed high importance on maintaining close ties with their Chinese counterparts in the host country. Hence cultural association with the U.S. played a negative role as did language proficiency and length of stay in the host nation. Our findings thus support the tendency to seek and maintain one's home culture in the process of acculturation as reported by Poyrazli (2003), Bektas et al. (2009), and Yu \& Wang (2011). As length of stay increases, choosing separation is less and less likely.

Having a pragmatic motivation to learn the language to be able to interact with the host country, but not to learn the language's culture, was found to be significantly positively correlated with marginalization but was also one of the smallest statistically significant effects and impacted, at least statistically significantly so, only the marginalization choice which was also the least frequent of preferred acculturation strategies.

Finally, assimilation, which was also infrequently observed as the leading acculturation strategy, was mainly influenced by a lack of Chinese cultural association.

Noteworthy in this study is the lack of statistical significance of demographic factors on acculturation strategy choice. Age, gender and academic level of degree sought, all showed insignificant impact on strategy choice which is different from results shown in prior studies (Neto, 2002; Wang \& Mallinckrodt, 2006; Yan \& Berliner, 2011) and suggests that targeting programmatic efforts of universities to lead to desired acculturation outcomes would not be aided by knowing age, gender or pursuit of degree program.

Also an interesting finding in this paper is the correlation between lessened experience of self-reported anxiety and depression and assimilation and marginalization choices. For assimilation, a coping mechanism appears to be disconnecting with the home culture. With marginalization cultural association with both home and host country is downplayed and thereby may lessen anxiety to conform to either culture. At the same time, marginalization had a great negative influence on social adaptation. Hence, integration likely comes at the cost of some anxiety. Difficult to ascertain from this type of study, however, are temporal effects of strategy choices. Since respondents were only surveyed once, it is difficult to determine cause and effects relationships among social adaptation and psychosomatic symptoms that may change over time and also the duration of psychosomatic symptoms, for example.

\section{Conclusion}

In sum, if social integration is the desired outcome of university exchange programs, it is clear from this study that enhanced language proficiency as well as encouragement to culturally identify with both the home and host nations are beneficial. As Ward \& Kennedy (1993) and Zhang \& Goodson (2011) suggest, more interaction with host nationals could reduce social adaptation difficulties. At the same time, length of stay was positively correlated with an integration strategy preference and hence promotion of language proficiency and cultural integration may well be offered at earliest convenience such as during orientation programs. While assimilation and marginalization strategies were positively correlated with lesser psychosomatic symptoms, there was no significant direct relationship with integration, suggesting further, that promotion of an integration strategy would be beneficial.

Further research might address temporal aspects of acculturation strategy choices on social adaptation as well as anxiety and depression symptoms. Further, analyzing responses across greater 
regional expanse in both the U.S. and asking more questions related to Chinese origin and family dynamics may lead to greater insight.

Despite these limitations, a clear implication emerged from this study. Formal language training for international students should be promoted to help improve their language proficiency, which can further facilitate their identification with the host country by developing better social skills and, thus, getting integrated in the host country's culture. Also, enhancing social adaptation skills by teaching stress coping techniques and emphasizing the importance of social interaction to gain new cultural insights would be helpful. Targeting Chinese students on the basis of gender and age to promote outcomes was not found to be effective in this study.

\section{References}

1. Allison, P. D. \& Christakis, N. (1994). Logit models for sets of ranked items. Sociological Methodology, 24, 199228.

2. Barry, D.T. (2001). Development of a new scale of measuring acculturation: The East Asian acculturation measure (EAAM). Journal of Immigrant Health, 3(4), 193-197.

3. Beggs, S., Cardell, S. \& Hausman, J. (1981). Assessing the potential demand for electric cars. Journal of Econometrics, 16(1), 1-19

4. Bektas, Y., Demir, A, \& Bowden, R. (2009). Psychological adaptation of Turkish students at U.S. campuses. International Journal for the Advancement of Counseling, 31(2), 130-143.

5. Berry, J.W., Kim, U., Power, S., Young, M. \& Bujaki, M. (1989). Acculturation attitudes in plural societies. Applied Psychology: An international review, 38(2), 185-206.

6. Berry, J.W. (1997). Immigration, acculturation and adaptation. Applied Psychology: An International Review, $46(1), 5-34$.

7. Berry, J. W. (2005). Acculturation: Living successfully in two cultures. International Journal of Intercultural Relations, 29(6), 697-712.

8. Berry, J.W., Phinney, J.S. , Sam, D.L. \& Veddar P. (2006). Immigrant youth: Acculturation, identity, and adaptation. Applied Psychology: An International Review, 55(3), 202-332.

9. Chapman, R. \& Staelin, R. (1982). Exploiting rank ordered choice set data within the Stochastic Utility Model" Journal of Marketing Research, 19(3), 288-301.

10. Croissant, Y. (2013). Mlogit: multinomial logit model. R package version 0.2-4. http://CRAN.Rproject.org $/$ package $=$ mlogit

11. Duru, E. \& Poyrazli, S. (2007). Personality dimensions, psychosocial-demographic variables, and English language competency in predicting level of acculturative stress among Turkish international students. International Journal of Stress Management, 14(1), 99-110.

12. Furnham, A. \& Bochner, S. (1982). Social difficulty in a foreign culture: An empirical analysis of culture shock. In S.Bochner(Ed.). Cultures in contact:Studies cross-cultural interaction, 161-198. Oxford: Pergamon Press.

13. Gardner R.C. \& Masgoret A. M. (2003). Attitude, motivation, and second language learning: A meta-analysis of studies conducted by Gardner and associates. Language Learning, 53(1), 167-210.

14. Graves, T. (1967). Psychological acculturation in a tri-ethnic community. South-Western Journal of Anthropology, 23(4), 337-350.

15. Hui, B. P. H., Chen, S. X., Leung, C. M., \& Berry, J. W. (2015). Facilitating adaptation and intercultural contact: The role of integration and multicultural ideology in dominant and non-dominant groups. International Journal of Intercultural Relations, 45, 70-84.

16. Hendrickson, B., Rosen, D., \& Aune, R. K. (2011). An analysis of friendship networks, social connectedness, homesickness, and satisfaction levels of international students. International Journal of Intercultural Relations, 35(3), 281-295.

17. Institute of International Education. (2017). Open doors 2017 Executive Summary. Retrieved on January 20, 2018, from https://www.iie.org/Why-IIE/Announcements/2017-11-13 Open-Doors-2017-Executive-Summary.

18. Leong, C. H., \& Ward, C. (2000). Identity conflict in sojourners. International Journal of Intercultural Relations, $24(6), 763-776$.

19. Lilien, D., G. Sueyoshi, C. Wilkins, J. Wong, G. Thomas, S. Yoo, E. Lee, K. Sadri, R. Erwin, G. Liang, P. Fuquay, R. Startz, R. Hall, R. Engle, S. Ellsworth, H. Kwakatsu, and J. Noh. (2015). EViews 9. IHS Global Inc, Irvine, CA. 
20. McFadden, D. (1974). Conditional logit analysis of qualitative choice behavior. P. Zarembka (Ed.). Frontiers in Econometrics. New York, NY:Academic Press.

21. McNair, D., Lorr, M., \& Droppleman, I. (1971). Profile of mood states. San Diego, CA: Educational and Industrial Testing Service.

22. Neto, F. (2002). Acculturation strategies among adolescents from immigrant families in Portugal. International Journal of Intercultural Relations, 26, 17-38.

23. Ng, T.K., Wang, K.W.C, \& W. Chan (2017). Acculturation and Cross-cultural adaptation: The moderating role of social support. International Journal of Intercultural Relations, 59, 19-30.

24. Nunnally, J. (1978). Psychometric theory (2nd ed.). New York, NY: McGraw-Hill, Inc.

25. Phinney, J.S. \& Devich-Navarro, M. (1997). Variations in bicultural identification among African American and Mexican American adolescents. Journal of Research on Adolescents, 7(1), 3-32.

26. Poyrazli, S. (2003). Ethnic identity and psychosocial adjustment among international students. Psychological Reports, 92(2), 512-514.

27. Punj, G.N. \& Staelin, R. (1978). The choice process for graduate business schools. Journal of Marketing Research, 15(4), 588-598.

28. Redfield, R., Linton, R., \& Herskovits, M.J. (1935). Memoradum for the study of acculturation. Amercian Anthoropoligist, 35, 149-152.

29. Spector, P. (1992). Summated rating scale construction: an introduction. SAGE Publications. Newbury Park, CA.

30. Wang, C.DC. \& Mallinckrodt, B. (2006). Acculturation, attachment, and psychosocial adjustment of Chinese/Taiwanese international students. Journal of Counselling Psychology, 53(4), 422-433.

31. Ward, C, \& A. Kennedy. (1993). Where's the culture in cross-cultural transition? Comparative studies of sojourner adjustment. Journal of Cross-cultural Psychology, 24(2), 221-249.

32. Ward, C., \& Kennedy, A. (1996). Crossing cultures: The relationship between psychological and sociocultural dimensions of cross-cultural adjustment. In J. Pandey, D. Sinha \& D. P. S. Bhawuk (Eds.), Asian contributions to cross-cultural psychology, 289-306. New Delhi: Sage.

33. Ward, C. \& Rana-Deuba, A. (1999). Acculturation and adaptation revisited. Journal of Cross Cultural Psychology, 30(4), 422-442.

34. Ward, C., \& Kennedy, A. (1999). The Measurement of Sociocultural Adaptation. International Journal of Intercultural Relations, 23(4), 659-677.

35. Wei, M., Heppner, P., Mallen, M.J., Ku, T.-Y., Liao, K. Y.-H., \& Wu, T.-F. (2007). Acculturative stress, perfectionism, years in the United States, and depression among Chinese students. Journal of Counselling Psychology, 54(4), 385-394.

36. Yan, K. \& Berliner, D.C. (2011). Chinese international students in the United States: demographic trends, motivations, acculturation features and adjustment challenges. Asia Pacific Education Review, 12(2), 173-184.

37. Yang, R. P-J, Noels, K. A., Saumure, K. D. (2006). Multiple routes to cross-cultural adaptation for international students: Mapping the paths between self-construals, English language confidence, and adjustment. International Journal of Intercultural Relations, 30(4), 487-506.

38. Yeh, C. J. \& Inose, M. (2003). International students' reported English fluency, social support satisfaction, and social connectedness as predictors of acculturative stress. Counselling Psychology Quarterly, 16(1), 15-28.

39. Ying, Y. (2005). Variation in acculturative stressors over time: A study of Taiwanese students in the United States. International Journal of Intercultural Relations, 29(1), 59-71.

40. Yu, W.H. \& Wang, S. (2011). An Investigation into the acculturation strategies of Chinese students in Germany. Intercultural Communications Studies, 20(2), 190-210.

41. Zhang, J., \& Goodson, P. (2011). Acculturation and psychosocial adjustment of Chinese international students: Examining mediation and moderation effects. International Journal of Intercultural Relations, 35(5), 614-627.

42. Zheng, X., Sang, D. \& Wang, L. (2004). Acculturation and subjective well-being of Chinese students in Australia. Journal of Happiness Studies, 5(1), 57-72.

43. Zhou, G., \& Zhang, Z. (2014). A study of the first year international students at a Canadian university: Challenges and experiences with social integration. Comparative and International Education, 43(2), Article 7.

44. Zhou, Y., Jindal-Snape D., Topping K. \& Todman J. (2008). Theoretical models of culture shock and adaptation in international students in higher education. Studies in Higher Education. 33(1), 63-75.

45. Zung, W.W.K. (1965). A self-rating depression scale. Archives of General Psychiatry, 12, 63-7 


\section{Appendix A}

\section{Questionnaire on acculturation strategies of Chinese university students in Arkansas}

Dear students,

This questionnaire is intended to investigate the acculturation strategies of Chinese university students in Arkansas. For the sake of research reliability, your honest answers will be expected and we do appreciate your time and effort involved. Your information will be kept confidential and used for this research only. Thanks again for your devotion!

\section{Personal information}

Gender:

Age of arrival in U.S.:

IELTS or TOEFL score if any:

Age:

Grade:

Length of stay in U.S.:

Other language proficiency test score if any:

How much do you agree or disagree with each of the following statements? Circle the one based on your own experience.

$\mathrm{SA}=$ Strongly agree; $\mathrm{A}=$ Agree; $\mathrm{N}=$ Neutral/not sure; $\mathrm{D}=$ Disagree; $\mathrm{SD}=$ Strongly disagree.

\section{Section A}

1. I behave like an American in many ways.

2. Most of the music I listen to is Chinese music.

3. I would like to marry an American as well as a Chinese.

SA A

SA A

SA A

4. Generally, I find it difficult to socialize with anybody, Chinese or American.

5. When I am in my apartment/house, I typically speak English.

SA A

SA A

SA A

SA A

SA A

7. I think as well in English as I do in Chinese.

8. I sometimes feel that neither Americans nor Chinese like me.

SA A

9. If I were asked to write poetry, I would prefer to write it in English. SA
10. I prefer going to social gatherings where most of the people are Chinese.

11. I have both American and Chinese close friends.

12. There are times when I think no one understands me.

SA A

SA A

SA A

SA A N

$\begin{array}{lll}\text { N } & \text { D } & \text { SD } \\ \text { N } & \text { D } & \text { SD } \\ \text { N } & \text { D } & \text { SD }\end{array}$

13. I get along better with American than Chinese.

14. I feel that Americans don't treat me the same as they socialize with other Americans.

15. I sometimes find it hard to communicate with people.

16. I feel that Americans understand me better than Chinese do.

$\mathrm{SA} \quad \mathrm{A} \quad \mathrm{N}$

$\mathrm{SA} \quad \mathrm{A}-\mathrm{N}-\mathrm{D}-\mathrm{SD}$

17. I would prefer to go out on a date with a Chinese than with an American.

18. I feel very comfortable around both Americans and Chinese.

SA $\quad$ A $\quad \mathrm{N} \quad \mathrm{D} \quad \mathrm{SD}$

19. I sometimes find it hard to make friends.

SA $\quad$ A $\quad \mathrm{N} \quad \mathrm{D} \quad \mathrm{SD}$

20. I find it easier to communicate with Americans than I do with Chinese.

SA $\quad$ A $\quad$ N $\quad$ D $\quad$ SD

21. I feel more relaxed when I am with a Chinese than I am with an American.

$\begin{array}{lllll}\mathrm{SA} & \mathrm{A} & \mathrm{N} & \mathrm{D} & \mathrm{SD}\end{array}$

22. Sometimes I feel that Chinese and Americans do not accept me. SA
23. I feel more comfortable socializing with Americans than I do with Chinese.

$\begin{array}{llllll} & \text { SA } & \text { A } & \text { N } & \text { D } & \text { SD } \\ \text { 24. Sometimes I find it hard to trust both Americans and Chinese. } & \text { SA } & \text { A } & \text { N } & \text { D } & \text { SD } \\ \text { 25. I like take part in both Chinese and non-Chinese social activities. } & \text { SA } & \text { A } & \text { N } & \text { D } & \text { SD } \\ \text { 26. I find that both Chinese and Americans often have difficulty understanding me. } & & \end{array}$

SA $\quad$ A $\quad \mathrm{N} \quad \mathrm{D} \quad \mathrm{SD}$

\section{Section B}


27. I study English well in order to be integrated into American society. SA A $\quad$ N $\quad$ D SD

28. I study English well in order to make more foreign friends. $\quad$ SA A $\quad$ N $\quad$ D $\quad$ SD

29. I study English well in order to understand American culture. $\quad$ SA A $\quad$ N $\quad$ D $\quad$ SD

30. I study English well for the sake of finding a good job. $\quad$ SA A $\quad$ N $\quad$ D $\quad$ SD

31. Studying English well is very important to both my studying and living.

SA $\quad \mathrm{A} \quad \mathrm{N} \quad \mathrm{D} \quad \mathrm{SD}$

32. I can understand Americans and respond to them well orally and in writing.

33. I can participate in class discussion in fluent English.

SA $\quad$ A $\quad \mathrm{N} \quad \mathrm{D} \quad \mathrm{SD}$

34. I feel it is very difficult to understand what my American teachers and friends say.

35. It is extremely difficult for me to write my thesis in English.

36. I can speak English without worrying about mistakes.

37. I can write English without worrying about mistakes.

38. I find memorizing English vocabulary easy.

39. I find understanding English grammar easy.

SA $\quad$ A $\quad$ N $\quad$ D $\quad$ SD

SA $\quad$ A $\quad$ N $\quad$ D $\quad$ SD

SA $\quad$ A $\quad$ N $\quad$ D $\quad$ SD

SA $\quad$ A $\quad$ N $\quad$ D $\quad$ SD

SA $\quad$ A $\quad \mathrm{N} \quad \mathrm{D} \quad \mathrm{SD}$

SA $\quad$ A $\quad \mathrm{N} \quad \mathrm{D} \quad \mathrm{SD}$

\section{Section C}

40. I prefer to be dressed in Western styles.

41. I prefer Western music to Chinese music.

42. I love Chinese culture, history and traditions.

43. Being part of the Chinese culture is embarrassing to me.

44. I sometimes find it hard to make friends.

45. Sometimes I feel tired for no reason.

46. Sometimes I have trouble sleeping at night.

47. In my daily life, I feel tense and anxious.

48. I feel lonely even if I am with people.

49. I am not used to the pace of life here.

50. I am threatened by belonging to different ethnic groups.

51. I feel unaccepted by the American people I know.

52. I feel uneasy when I am with people.

53. I feel more irritable than usual.

$\begin{array}{lllll}\text { SA } & \text { A } & \text { N } & \text { D } & \text { SD } \\ \text { SA } & \text { A } & \text { N } & \text { D } & \text { SD } \\ \text { SA } & \text { A } & \text { N } & \text { D } & \text { SD } \\ \text { SA } & \text { A } & \text { N } & \text { D } & \text { SD } \\ \text { SA } & \text { A } & \text { N } & \text { D } & \text { SD } \\ \text { SA } & \text { A } & \text { N } & \text { D } & \text { SD } \\ \text { SA } & \text { A } & \text { N } & \text { D } & \text { SD } \\ \text { SA } & \text { A } & \text { N } & \text { D } & \text { SD } \\ \text { SA } & \text { A } & \text { N } & \text { D } & \text { SD } \\ \text { SA } & \text { A } & \text { N } & \text { D } & \text { SD } \\ \text { SA } & \text { A } & \text { N } & \text { D } & \text { SD } \\ \text { SA } & \text { A } & \text { N } & \text { D } & \text { SD } \\ \text { SA } & \text { A } & \text { N } & \text { D } & \text { SD } \\ \text { SA } & \text { A } & \text { N } & \text { D } & \text { SD }\end{array}$

\section{Appendix B}

\section{Rank-Ordered Logit Model}

The rank-ordered logit model is a generalization of the conditional logit regression model introduced by McFadden (1974). In economics, Beggs et al. (1981) began using this generalization. Independently, the so-called "exploded logit model" was used in marketing research by Punj \& Staelin (1978) and Chapman \& Staelin (1982). The name "exploded logit model" is somewhat preferred because rank-ordered logit is easily confused with the cumulative logit model (aka ordered logit). The typical use of the exploded logit model has been in choice analysis where subjects are asked to rank their preferences for a fixed set of items. It has also gained some popularity in the social sciences (Allison \& Christakis, 1994). In the use of the model in this article, we assign rankings based on the subject's scores for each strategy.

Let $\Omega=\{A, S, I, M\}$ be the set of items representing the strategies assimilation, separation, integration, and marginalization, respectively. The rank-ordered logit model used in this article is based upon the utility model where subject $i$ has utility $U_{i j}$ for strategy $j$ given by:

$$
U_{i j}=\beta_{j} x_{i}+\epsilon_{i j}
$$

where the $\epsilon_{i j}$ 's are independent and identically distributed with an extreme-value distribution, $x_{i}$ is the column vector associated to the individual, and $\beta_{j}$ is a row vector of coefficients associated with strategy $j$. We assume subject $i$ ranks item $j$ above item $k$ (has a higher score for strategy $j$ than strategy $k$ in $\Omega$ ) whenever $U_{i j}>U_{i k}$. This basic set up is the same as the multinomial logit model. However, the differences come from the computation of probabilities. Probabilities are computed for sequences of rankings in the 
following manner. Let $Y_{i j_{1}}$ be the event that subject $i$ has strategy $j_{1}$ ranked highest among all four strategies. Then,

$$
\log \left(\frac{\operatorname{Pr}\left(\mathrm{Y}_{\mathrm{ij}_{1}}=1 \mid \mathrm{x}_{\mathrm{i}}\right)}{\operatorname{Pr}\left(\mathrm{Y}_{\mathrm{iI}}=1 \mid \mathrm{x}_{\mathrm{i}}\right)}\right)=\beta_{\mathrm{j}_{1}} \mathrm{X}_{\mathrm{i}}, \text { for } \mathrm{j}_{1} \in \Omega
$$

Here we have used $I$ (integration) as the baseline strategy since it is by far more common than any other strategy (Table 4). This implies that $\beta_{I}=0$. To make use of the other rankings, we then must look at $Y_{i j_{2}}$, the event that subject $i$ has strategy $j_{2}$ ranked second highest among the three remaining strategies.

$$
\log \left(\frac{\operatorname{Pr}\left(Y_{i j_{2}}=1 \mid x_{i}\right)}{\operatorname{Pr}\left(Y_{i I}=1 \mid x_{i}\right)}\right)=\beta_{j_{2}} x_{i}, \text { for } j_{2} \in \Omega /\left\{j_{1}\right\}
$$

Likewise for the third highest ranked strategy, we have

Manipulating these expressions gives:

$$
\log \left(\frac{\operatorname{Pr}\left(Y_{i j_{3}}=1 \mid x_{i}\right)}{\operatorname{Pr}\left(Y_{i I}=1 \mid x_{i}\right)}\right)=\beta_{j_{3}} x_{i}, \text { for } j_{3} \in \Omega /\left\{j_{1}, j_{2}\right\}
$$

and

$$
\begin{gathered}
\operatorname{Pr}\left(Y_{i j_{1}}=1 \mid x_{i}\right)=\frac{\exp \left(\beta_{j_{1}} x_{i}\right)}{\sum_{k \in \Omega} \exp \left(\beta_{k} x_{i}\right)}, \\
\operatorname{Pr}\left(Y_{i j_{2}}=1 \mid x_{i}\right)=\frac{\exp \left(\beta_{j_{2}} x_{i}\right)}{\sum_{h \in \Omega /\left\{j_{1}\right\}} \exp \left(\beta_{h} x_{i}\right)},
\end{gathered}
$$

$$
\operatorname{Pr}\left(Y_{i j_{3}}=1 \mid x_{i}\right)=\frac{\exp \left(\beta_{j_{3}} x_{i}\right)}{\sum_{l \in \Omega /\left\{j_{1}, j_{2}\right\}} \exp \left(\beta_{l} x_{i}\right)} .
$$

The fourth probability is necessarily 1 as there would only be one alternative left. Finally, the probability that subject $i$ has rankings $\mathrm{R}=\left\{\mathrm{j}_{1}, \mathrm{j}_{2}, \mathrm{j}_{3}, \mathrm{j}_{4}\right\}$ is the product

$$
\operatorname{Pr}\left(R_{i}=R \mid x_{i}\right)=\operatorname{Pr}\left(Y_{i j_{1}}=1 \mid x_{i}\right) \cdot \operatorname{Pr}\left(Y_{i j_{2}}=1 \mid x_{i}\right) \cdot \operatorname{Pr}\left(Y_{i j_{3}}=1 \mid x_{i,}\right),
$$

and the log-likelihood function is built in the usual way by summing over all individuals. In Beggs et al. (1981), the likelihood function was shown to be globally concave ensuring any local maximum found would in fact be the global maximum. Most statistical programs can estimate the rank-ordered model provided the data is set up correctly. We used the "mlogit" package of $R$ to estimate the rank-ordered logit model (Croissant, 2013).

When interpreting the model, it is important to note that the estimated coefficient vectors $\widehat{\beta_{s}}, \widehat{\beta_{A}}$, and $\widehat{\beta_{\mathrm{M}}}$ are the same regardless of whether they appear in equations [2], [3], or [4]. The typical approach to interpretation is to focus more on equation [2] where coefficients can be interpreted exactly as in a multinomial logit model. That is to say, for example, the odds ratio that an individual (with characteristics $x$ ) has assimilation strategy ranked highest as opposed to having integration strategy highest is estimated by $\exp \left(\widehat{\beta_{\mathrm{A}}} \mathrm{x}\right)$.

Marginal effects are given by the change in probability with respect to a change in a covariate. For continuous variables, this is simply the partial derivative of the probability function with respect to $\beta$. For a categorical variable, the marginal effect is the difference in probabilities given by the model as the covariate changes categories from the base level category. In this paper, marginal effects are computed at the vector of mean values for continuous variables and the base value for categorical variables and divided by the probability of that vector for the appropriate scaling. The significance of marginal effects was determined by bootstrap sampling of 1000 samples followed by a Wald test on the mean of the marginal effects. 